RESEARCH PAPER RP792

Part of Journal of Research of the National Bureau of Standards, Volume 14, May 1935

\title{
THERMAL BEHAVIOR OF THE KAOLIN MINERALS
}

\author{
By Herbert Insley and Raymond H. Ewell
}

\section{ABSTRACT}

When minerals of the kaolin group are heated at constant rates there are two principal heat effects, a broad, pronounced endothermic effect near $5.50^{\circ} \mathrm{C}$ and a sharp, intense exothermic effect near $950^{\circ} \mathrm{C}$. New evidence, based largely on $\mathrm{X}$-ray patterns of the kaolin minerals and of artificial alumina-silica gels after various heat treatments, leads to the following conclusions: (1) The endothermic effect is due to the dissociation of the kaolin minerals into water vapor and an intimate mixture of amorphous $\mathrm{Al}_{2} \mathrm{O}_{3}$ and amorphous $\mathrm{SiO}_{2}$; (2) The exothermic effect is caused by the crystallization of $\gamma-\mathrm{Al}_{2} \mathrm{O}_{3}$ from amorphous $\mathrm{Al}_{2} \mathrm{O}_{3}$; (3) The delay in the crystallization of $\gamma-\mathrm{Al}_{2} \mathrm{O}_{3}$ until higher temperatures are reached and the resultant intensity of the effect produced are due to the restraining action of the rigid amorphous $\mathrm{SiO}_{2}$ network with which the $\mathrm{Al}_{2} \mathrm{O}_{3}$ is closely associated.

\section{CONTENTS}

I. Introduction

II. Materials investigated

III. Experimental methods _.

IV. Data and discussion

1. Introductory $\ldots \ldots \ldots \ldots$

2. The endothermic heat effect 619

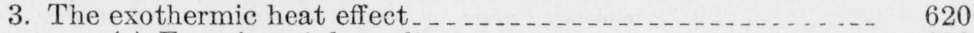

(a) Experimental results

(b) The nature of dehydrated kaolin ............. 624

(c) Discussion of results_................... 625

V. Summary

\section{INTRODUCTION}

Since Le Chatelier's ${ }^{1}$ discovery of the thermal effects obtained when clays are heated, there have been numerous investigations ${ }^{2}$ to determine the cause of these effects, and at least three distinct theories have been developed. Much of the resulting confusion has been caused by: (1) The use of materials which contained large amounts of impurities or which were mixtures of different species of clay minerals; (2) Unfortunate selection of the experimental methods; (3) The assumption that samples heated at constant temperature for long periods of time contain the same phases as samples withdrawn from the furnace immediately at the attainment of that temperature.

A part of the confusion has been eliminated by the work of Ross and Kerr, ${ }^{3}$ who discovered the existence of three minerals of the kaolin

1 Z. Phys. Chem. 1, 396 (1887).

2 A comprehensive review of the theories and the experimental work is given by K. Spangenberg, Keram. Rundschau 35, 331-335, 352-354, 370-372 (1927).

3 The Kaolin Minerals, U. S. Geol. Survey Professional Papers 165-E (1930). 
group, nacrite, dickite, and kaolinite, with the same chemical composition $\left(\mathrm{Al}_{2} \mathrm{O}_{3} .2 \mathrm{SiO} .2_{2} \mathrm{H}_{2} \mathrm{O}\right)$ but with distinctive crystal structures. ${ }^{4}$

The purpose of the present work has been to determine more precisely the nature of the heat effects when clay minerals are heated at controlled rates and to discover the changes in structure and constituents which accompany these heat effects.

\section{MATERIALS INVESTIGATED}

Two kaolin minerals, dickite and kaolinite, were the natural materials on which most of the experiments reported here were made. The heat effects in various other clays were observed for comparison, but because of the lack of knowledge of their constitution and purity the results were inconclusive. The dickite, obtained through the courtesy of W. F. Foshag, of the U. S. National Museum, was from the National Belle Mine, Red Mountain, Colo. The material occurs as a loose powder, and with a low-power microscope it is found to be made up of individual crystals with perfect basal cleavage and hexagonal outline. The kaolinite chosen for these experiments was the washed Zettlitz kaolin distributed as an international standard by the Ceramic Society of Czechoslovakia. The optical and crystallographic properties of these two kaolin minerals are given by Ross and Kerr. ${ }^{5}$ Chemical analyses are given in table 1 .

TABLE 1.-Chemical analyses of kaolin minerals

\begin{tabular}{|c|c|c|c|c|c|}
\hline Constituents & $\begin{array}{l}\text { Zettlitz } \\
\text { kaolin }{ }^{a}\end{array}$ & $\begin{array}{c}\text { Red } \\
\text { Mountain } \\
\text { dickite }^{b}\end{array}$ & Constituents & $\begin{array}{l}\text { Zettlitz } \\
\text { kaolin } a\end{array}$ & $\begin{array}{c}\text { Red } \\
\text { Mountain } \\
\text { dickite }^{b}\end{array}$ \\
\hline $\begin{array}{l}\mathrm{SiO}_{2} \\
\mathrm{Al}_{2} \mathrm{O}_{3} \\
\mathrm{Fe}_{2} \mathrm{O}_{3} \\
\mathrm{P}_{2} \mathrm{O}_{5} \\
\mathrm{TiO}_{2} \\
\mathrm{Z}_{\mathrm{rO}} \\
\mathrm{MnO} \\
\mathrm{CaO} \\
\mathrm{MgO}\end{array}$ & $\begin{array}{r}\text { Percent } \\
46.90 \\
37.40 \\
.65 \\
.08 \\
.18 \\
.007 \\
.007 \\
.29 \\
.27\end{array}$ & $\begin{array}{r}\text { Percent } \\
46.35 \\
39.59 \\
.11 \\
\\
\\
\end{array}$ & $\begin{array}{l}\mathrm{Cr}_{2} \mathrm{O}_{3} \\
\mathrm{~V}_{2} \mathrm{O}_{3} \\
\mathrm{~K}_{2} \mathrm{O}_{2} \\
\mathrm{Na}_{2} \mathrm{O}_{2} \\
\mathrm{SO}_{3} \\
\mathrm{~F} \leftrightharpoons \mathrm{C}=\mathrm{O}\end{array}$ & $\begin{array}{r}\text { Percent } \\
.015 \\
.002 \\
.84 \\
.44 \\
.03 \\
12.95\end{array}$ & $\begin{array}{r}\text { Percent } \\
0.06 \\
13.93\end{array}$ \\
\hline $\begin{array}{l}\mathrm{BaO} \\
\mathrm{SrO}\end{array}$ & $\begin{array}{l}.27 \\
.02 \\
.006\end{array}$ & - & Totals & 100.087 & 100.13 \\
\hline
\end{tabular}

a Analysis from BS Tech. News Bul. 138, p. 146 (1928).

b W. F. Hillebrand, analyst, U. S. Geol. Survey Bul. 20, p. 97 (1885).

Synthetic materials studied included five $\mathrm{Al}_{2} \mathrm{O}_{3}-\mathrm{SiO}_{2}$ coprecipitated gels with approximate $\mathrm{Al}_{2} \mathrm{O}_{3}: \mathrm{SiO}_{2}$ ratios of $1: 4,1: 2,1: 1,2: 1$, and $4: 1$, and four other mixed gels, gels $\mathrm{A}, \mathrm{B}, \mathrm{C}$, and $\mathrm{D}$, all with $\mathrm{Al}_{2} \mathrm{O}_{3}: \mathrm{SiO}_{2}$ equal to 1:2. The coprecipitated gels were prepared as follows. An analyzed solution of sodium silicate (containing $68 \mathrm{~g}$ of $\mathrm{SiO}_{2}$ per liter) was measured out and solid $\mathrm{Al}_{2}\left(\mathrm{SO}_{4}\right)_{3} \cdot 18 \mathrm{H}_{2} \mathrm{O}$ was weighed out in proportions to give the desired molar ratio. The salt was dissolved in water (about $100 \mathrm{cc}$ per $4 \mathrm{~g}$ of salt) and the silicate solution added dropwise with vigorous stirring. Then 10 percent $\mathrm{NaOH}$ solution was added to neutrality as shown by phenol red indicator. The voluminous, gelatinous precipitate was filtered, dried, ground to pass

${ }^{4}$ J. W. Gruner, Crystal structure of kaolinite. Z. Kryst. 83, 75-88 (1933); Crystal structure of dickite. Z. Kryst. 83, 394-404 (1932); Crystal structure of nacrite and a comparison of certain optical properties of the kaolin group with its structure. Z. Kryst. 85, 345-354 (1933).

s The Kaolin Minerals, U. S. Geological Survey Professional Papers 165-E (1930). 
a no. 200 sieve, washed thoroughly on a filter with hot water and redried at $110^{\circ} \mathrm{C}$. Analysis of three of the $1: 2$ gel preparations gave $\mathrm{Al}_{2} \mathrm{O}_{3}: \mathrm{SiO}_{2}$ ratios of $1: 1.99,1: 1.90$, and $1: 1.88$, respectively. A soda determination on the $1: 1.88$ product showed it to contain 0.65 percent of $\mathrm{Na}_{2} \mathrm{O}$. Therefore, another 1:2 gel was made, using aluminum chloride instead of aluminum sulphate, and the product was electrodialyzed for 10 hours in a Bradfield two-compartment electrodialysis cell to free it of sodium ions. Analysis after this treatment gave 0.09 percent of $\mathrm{Na}_{2} \mathrm{O}$. All these coprecipitated gels were found to consist of clear, angular, isotropic grains when examined under the microscope. $\mathrm{X}$-ray photographs showed them to be amorphous. The $\mathrm{Al}_{2} \mathrm{O}_{3}$ in these gels was completely soluble in dilute $\mathrm{HCl}$.

Other mixed gels were made as follows:

Gel A.- $\mathrm{Al}_{2} \mathrm{O}_{3}$ and $\mathrm{SiO}_{2}$ gels were precipitated in separate vessels, allowed to settle, and, after decanting, mixed together with vigorous stirring. The combined precipitate was then filtered and the gel cake mashed thoroughly in a mortar. The product was ground and washed with hot water as described above.

Gel B.-Finely ground (through a no. 325 sieve) dried $\mathrm{Al}_{2} \mathrm{O}_{3}$ and dried $\mathrm{SiO}_{2}$ gels were mixed in weighed proportions, moistened, and ground thoroughly in a mortar for two hours.

Gel C.- Fine (through a no. 325 sieve) particles of dried $\mathrm{Al}_{2} \mathrm{O}_{3}$ gel were suspended in water. Sodium silicate solution and dilute $\mathrm{HCl}$ solution were then added drop by drop simultaneously so that the solution was always kept neutral. Silica gel precipitated around each $\mathrm{Al}_{2} \mathrm{O}_{3}$ particle giving a voluminous flocculent precipitate.

Gel D.-Prepared the same as gel $\mathrm{C}$ except that the $\mathrm{Al}_{2} \mathrm{O}_{3}$ gel was first heated to $800^{\circ} \mathrm{C}$ for 24 hours, thereby converting it to $\gamma-\mathrm{Al}_{2} \mathrm{O}_{3}$.

\section{EXPERIMENTAL METHODS}

Thermal effects were measured by the Le Chatelier differential thermocouple method. A platinum-wire resistance furnace, a divided platinum cylinder, a Pt-Rh to Pt to Pt-Rh differential thermocouple, and a type $\mathrm{K}$ potentiometer were used. Artificial alpha-alumina, known to show no measurable heat effects, was used as a reference material. The furnace temperature was increased at a constant rate by manually decreasing the resistance in series with the furnace at regular time intervals. The normal heating rate selected was $6^{\circ}$ $\mathrm{C} / \mathrm{min}$, but rates between 1 and $25^{\circ} \mathrm{C}$ per minute were also used. Readings of the temperature of the sample and of the galvanometer deflection due to the temperature difference between the two sides of the cylinder were made at intervals of 1 minute or less. These readings were plotted in the usual manner as shown in figures 1 and 4 .

Determinations of the crystalline compounds present in the samples were made by comparison of X-ray powder diffraction patterns, using either a Coolidge type tube with Mo $K \alpha$ radiation and a camera of $20.8-\mathrm{cm}$ radius, or an ion tube of the type developed by Ksanda ${ }^{6}$ with $\mathrm{Cu} K \alpha$ radiation and a camera of $4.1-\mathrm{cm}$ radius. Cameras for both tubes were so arranged that comparison patterns of two materials could be photographed on the same film.

\footnotetext{
${ }^{6}$ Rev. Sci. Instr. 3, 531-534 (1932).
} 
Supplemental examinations were made with the petrographic microscope, but in most cases the materials were so fine grained that the results were not conclusive.

\section{DATA AND DISCUSSION}

\section{INTRODUCTORY}

When samples of dickite or kaolinite are heated at an approximately constant rate of $6^{\circ} \mathrm{C} / \mathrm{min}$, three heat effects are observed (fig. 1), which in order of occurrence with increasing temperature are: (1) A large endothermic effect which occurs over a broad temperature range;

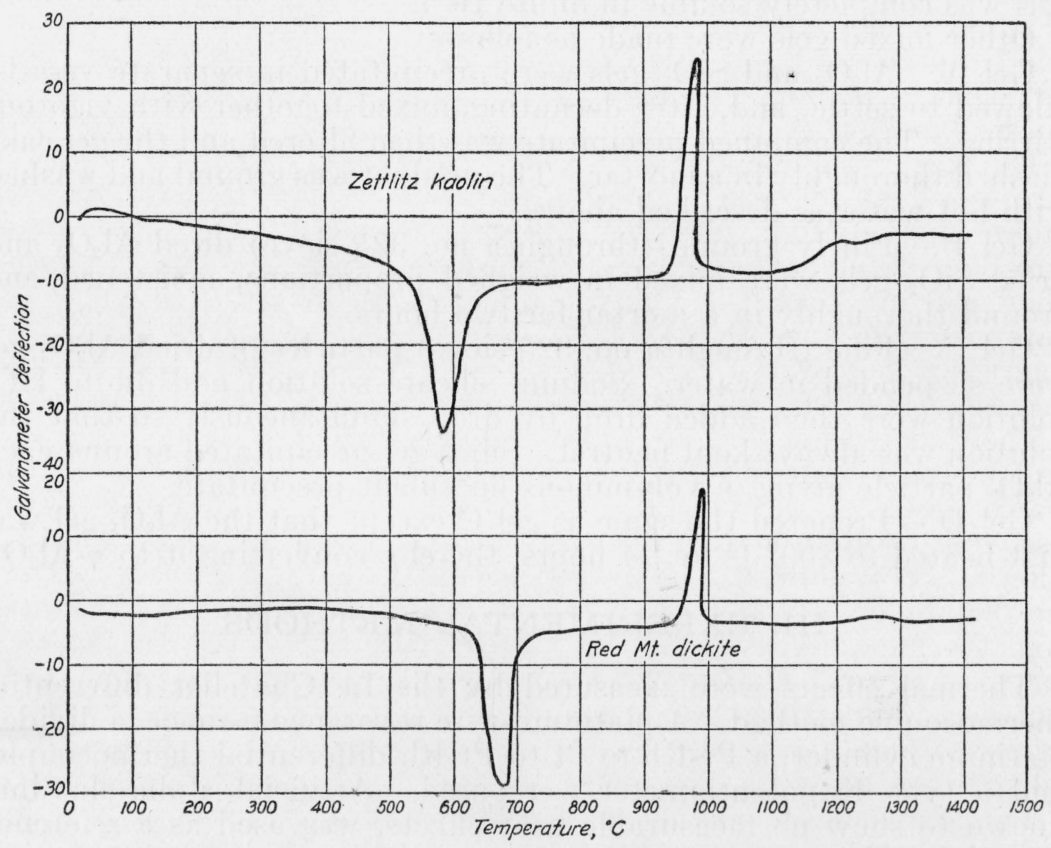

FIGURE 1.-Heating curves of kaolinite and dickite.

(2) a large exothermic effect which is very sharp and intense and occurs over a narrow temperature range; (3) a very small exothermic effect which occurs over a broad temperature range and which is frequently difficult to detect.

When a sample which has been heated to any temperature is cooled no heat effects are observed during the cooling; when the sample is reheated no heat effects are observed up to that temperature, but the heat effects above that temperature are unaffected. Therefore, all of the reactions causing these heat effects are irreversible.

This paper is concerned with the first two of these heat effects. ${ }^{7}$

7 The third heat effect begins at about $1,150^{\circ} \mathrm{C}$ and ends at about $1,250^{\circ} \mathrm{C}$. Since it is evidenced in $\mathrm{X}$-ray patterns only by an intensification of the mullite lines, it probably represents the temperature range in which the formation of mullite takes place most rapidly. 


\section{THE ENDOTHERMIC HEAT EFFECT}

The endothermic effect occurs over a wide temperature range from about 450 to about $580^{\circ} \mathrm{C}$ in Zettlitz kaolin and from about 550 to about $680^{\circ} \mathrm{C}^{8}$ in Red Mountain dickite. This heat absorption is definitely related to the loss of "combined" water, as has been shown by Sokoloff, ${ }^{9}$ Tammann and Pape, ${ }^{10}$ Rhode, ${ }^{11}$ van Nieuwenburg and Pieters, ${ }^{12}$ and Nutting. ${ }^{13}$ All of these investigators made determinations of weight losses at constant temperatures, and all of them obtained values in fair agreement for experiments carried out in contact with the room atmosphere. A few experiments on dickite and kaolinite made in this investigation also confirm these results. The results of all agree in showing that the dehydration takes place over a considerable temperature range and that with constantly increasing temperature there is no single temperature at which all the combined water can be expelled.

The most complete and decisive work on the dehydration temperature was done by van Nieuwenburg and Pieters who, using Zettlitz kaolin and Neurode pholerite (dickite), measured the vapor pressures for different temperatures and for different water contents. They conclude that: (1) The dissociation pressure is a function of the water content over the whole range of dissociation; (2) The $p-t-x$ diagram is not a true equilibrium diagram because, in part, of the very small particle size of ordinary kaolin.

Their conclusion that the water loss of Neurode pholerite at significantly higher temperatures than that of Zettlitz kaolin is due to the coarser grain of the former, is open to some doubt because of the discovery by Ross and Kerr ${ }^{14}$ that Neurode pholerite (dickite) has a different crystalline structure from Zettlitz kaolin (kaolinite). That the dickite investigated does lose its water at higher temperatures than the kaolinite available for study is shown also by the heating curves of figure 1 and by the weight-loss temperature experiments of Nutting. ${ }^{15}$ The final solution of this part of the problem awaits a supply of pure kaolinite of uniform coarse grain for measurements of dehydration temperatures under controlled water-vapor pressures.

The knowledge available on the dehydration relations of the dissociation process assists very little in answering the question as to the nature of the dissociation process. To determine the nature of the products, samples of kaolinite and dickite were heated at $6^{\circ} \mathrm{C} / \mathrm{min}$ to temperatures at which the original X-ray pattern had completely disappeared, namely, from $700^{\circ} \mathrm{C}$ up to the beginning of the exothermic effect (about $925^{\circ} \mathrm{C}$ ). Samples air-quenched from temperatures in this range gave no X-ray patterns attributable to crystalline materials; the patterns all consisted of a broad, diffuse band characteristic of amorphous materials.

${ }_{8}$ These values represent, respectively, the beginning of rapid absorption of heat and the temperature at which the absorption is complete (minimum on the differential heating curve) for the particular experimental conditions. Different experimental conditions, especially different heating rates, will change these values somewhat. The temperature representing the beginning of rapid absorption of heat is indefinitely located on the curve and hence difficult of reproduction. The temperature at which the absorption is complete is definitely located on the curve and can be reproduced to within $\pm 3^{\circ} \mathrm{C}$ with the same material, apparatus, and heating rate.

9 Tonind. Z. 36, 1107-1110 (1912).

10 Z. anorg. allgem. Chem. 12\%, 43-68 (1923)

11 Keram. Rundschau 35, 398-401, 414-415, 434-435, 452-454, 470-471 (1927).

12 Rec. trav. Chim. 48, 406-416 (1929).

13 The Bleaching Clays. U. S. Geol. Survey Cir. 3 (1933).

14 The Kaolin Minerals. U. S. Geol. Survey Professional Papers 165-E (1930).

15 The Bleaching Clays. U. S. Geol. Survey Cir. 3 (1933). 
The only direct evidence that a crystalline material results from the dehydration of kaolin is that of Hyslop and Rooksby, ${ }^{16}$ who found that samples of English china clay when heated to temperatures between $650^{\circ}$ and $850^{\circ} \mathrm{C}$ gave a diffraction pattern of a crystalline material, which they called "alpha" and which they assumed to be a crystalline anhydrous alumino-silicate, probably $\mathrm{Al}_{2} \mathrm{O}_{3} \cdot 2 \mathrm{SiO}_{2}$. English china clay is known to be a somewhat impure kaolin, and petrographic examination $\mathrm{s}^{17}$ have shown that a sample of washed English china clay contained about 10 percent of muscovite mica. A sample of this clay in one compartment of a divided crucible with muscovite mica in the other compartment was heated to $750^{\circ} \mathrm{C}$ at $12^{\circ} \mathrm{C} / \mathrm{min}$ and air-quenched. The sample afforded a faint X-ray diffraction pattern, five lines of which could be readily distinguished and measured. These lines were identical in position with the five strongest lines of the pattern of the muscovite mica heated simultaneously and their calculated positions agreed well with those given by Hyslop and Rooksby in a diagram of the "alpha" pattern.

Since dehydrated kaolin is amorphous, and not crystalline, the question arises as to whether it is: (1) An intimate mixture of amorphous alumina and amorphous silica; (2) An amorphous compound of alumina and silica (anhydro-kaolin or meta-kaolin).

Both of these hypotheses have been advanced in the literature. ${ }^{18}$ In section IV-3 (b) evidence will be advanced in support of the first hypothesis.

The only evidence of any phase changes between the temperatures of the endothermic and exothermic heat effects is that given by Schwarz and Klos. ${ }^{19}$ They postulate a phase change at $870^{\circ} \mathrm{C}$ based solely on very small inflections in the thermal-expansion curve of clays. Such inflections do not necessarily represent changes in phase. The most sensitive methods of detecting thermal effects which have been used on the clay minerals, those of Houldsworth and $\mathrm{Cobb}^{20}$ and ourselves, fail to show any effects at or near $870^{\circ} \mathrm{C}$.

\section{THE EXOTHERMIC HEAT EFFECT}

(a) EXPERIMENTAL RESULTS

The exothermic effect is a rapid evolution of heat beginning at about $925^{\circ} \mathrm{C}$ and, with a heating rate of $6^{\circ} \mathrm{C} / \mathrm{min}$, reaching a maximum at $985^{\circ} \mathrm{C}^{21}$ Under the conditions of the present experiments the increase of temperature of the sample over that of the reference material may be as much as $30^{\circ} \mathrm{C}$. The characteristics of the effect, including temperature and intensity, are identical for kaolinite and dickite. For heating rates between 1 and $20^{\circ} \mathrm{C} / \mathrm{min}$ the temperature of the beginning of heat evolution does not vary more than $4^{\circ} \mathrm{C}$, but because of the rate at which the heat is evolved, the temperatures of the maximum may be widely different, ranging from $957^{\circ} \mathrm{C}$ for a heating rate of $1^{\circ} \mathrm{C} / \mathrm{min}$ to $1,013^{\circ} \mathrm{C}$ for a heating rate of $20^{\circ} \mathrm{C} / \mathrm{min}$.

\footnotetext{
16 Trans. Ceram. Soc. 27, 93-96 (1927-1928).

17 R. H. Ewell, BS J. Research 8, 202 (1932) RP 410

18 Mellor and Holdcroft, Trans. Ceram. Soc. 10, 94 (1911), first advanced the hypothesis of the decomposition into alumina, silica and water on the evidence of similarities in the properties of amorphous alumina and dehydrated kaolinite.

19 Z. anorg. Chem. 196, 213-219 (1931).

20 Trans. Ceram. Soc. 22, 111-137 (1922-23).

${ }^{21}$ See footnote 8, p. 619 . The reproducibility in this case is $\pm 4^{\circ} \mathrm{C}$ for the lower temperature and $\pm 2^{\circ} \mathrm{C}$ or the upper temperature, with the same material, apparatus, and heating rate.
} 
In order to show the changes in phase which accompany the exothermic effect, samples of kaolinite and dickite were heated at $6^{\circ} \mathrm{C} / \mathrm{min}$ to temperatures just below the beginning of the effect $\left(925^{\circ} \mathrm{C}\right)$ and air-quenched. Other samples of the same materials were heated to the point where the maximum of the effect was evidenced and air-quenched. Those samples air-quenched before the exothermic effect showed no crystalline X-ray pattern; those airquenched at the maximum of the effect showed a faint but identifiable pattern of crystalline $\gamma=\mathrm{Al}_{2} \mathrm{O}_{3} .{ }^{22}$ Samples air-quenched after the temperature of the sample had returned to the temperature of the reference material (at about $1,000^{\circ} \mathrm{C}$ ) showed a faint $\mathrm{X}$-ray pattern of mullite ${ }^{23}$ in addition to $\gamma=\mathrm{Al}_{2} \mathrm{O}_{3}$. These results are shown in table 2 and figure 2.

TABLE 2.-Crystalline phases indicated by $X$-ray patterns in the heat-treated kaolin minerals and gels giving an exothermic heat effect

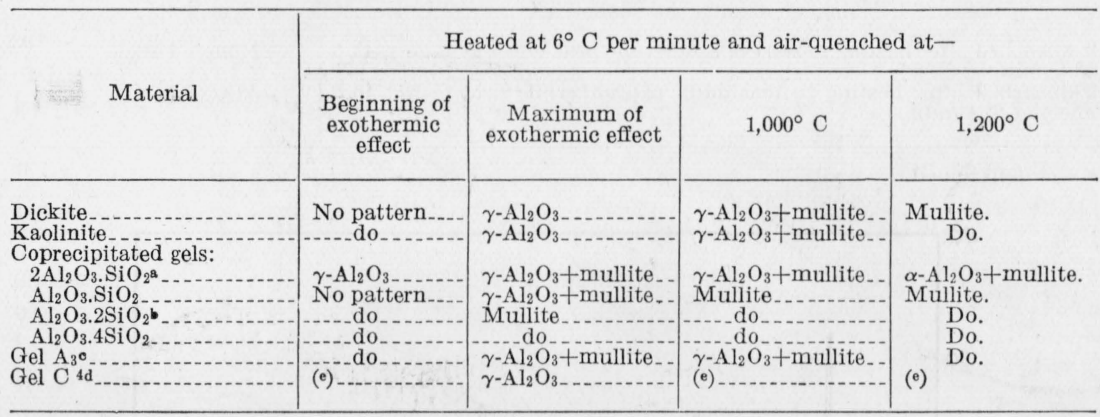

a No pattern after air-quenching at $903^{\circ} \mathrm{C}$.

b The $\mathrm{Al}_{2} \mathrm{O}_{3} \cdot \mathrm{SiO}_{2}$ gel made from aluminum chloride and electrodialyzed gave the same results as the other coprecipitated gels of approximately this composition.

- Made by mixing gelatinous alumina and gelatinous silica and drying.

d Made by precipitating silica about fine particles of dried alumina gel in suspension.

e Not determined.

Heat treatment of the kaolin minerals at constant temperature below $925^{\circ} \mathrm{C}$ reduces the intensity of the exothermic heat effect to varying degrees, depending on the temperature and time of preheating. No strictly quantitative comparisons can be made since the size of the exothermic effect depends so much upon the centering of the thermocouple junctions in the sample and upon slight variations in the heating rate, but a relation is evident from figure 3 and table 3 , which show the dependence of the size of the exothermic effect upon the preliminary heat treatment in. samples of Zettlitz kaolin. ${ }^{24}$ It is apparent that there is, in general, a decrease in the size of the exothermic effect with increase in the temperature of the preliminary heat treatment.

Also, the amount of acid-soluble alumina ${ }^{25}$ in heat-treated samples, including both samples heated at constant temperatures and samples air-quenched upon reaching a given temperature, shows a relation to

${ }^{22} \mathrm{~A}$ modification of crystalline $\mathrm{Al}_{2} \mathrm{O}_{3}$ first described by Ulrich, Norsk Geol. Tids. 8, 122 (1925). The X-ray patterns obtained were identical with those given by Hansen and Brownmiller, Am. J. Sci. 15, 225-242 (1928), and by Brill, Z. Krist. 83, 323-325 (1932).

23 Although we have designated this pattern as mulite, there are not sufficient lines to decide whether the pattern is that of mullite or of sillimanite. On the basis of the discussion of Posnjak and Greig, J. Am. Ceram. Soc. 16, 569-583 (1933), we have preferred to call it mullite.

24 See also H. S. Houldsworth and J. W. Cobb, Trans. Ceram. Soc. 23, 288 (1923-24).

25 Our method of determination of $\mathrm{Al}_{2} \mathrm{O}_{3}$ soluble in $\mathrm{HCl}$ was that of Rhode, Keram. Rundschau 35, 400 (1927), and our results agree well with hers. 
the heat treatment which parallels that of the intensity of the exothermic effect and of the appearance of $\gamma-\mathrm{Al}_{2} \mathrm{O}_{3}$ (table 3).

TABLE 3.-Relation of temperature and time of heat treatment to amount of "soluble $\mathrm{Al}_{2} \mathrm{O}_{3}$ ", X-ray pattern, and size of exothermic effect in samples of Zettlitz kaolin

\begin{tabular}{|c|c|c|c|c|}
\hline \multicolumn{2}{|l|}{ Preliminary heat treatment } & \multirow{2}{*}{$\begin{array}{l}\text { Amount of } \\
\text { "Soluble } \\
\mathrm{Al}_{2} \mathrm{O}_{3} "\end{array}$} & \multirow{2}{*}{$\begin{array}{c}\text { Crystalline } \\
\text { phase } \\
\text { indicated } \\
\text { by X-ray } \\
\text { pattern }\end{array}$} & \multirow{2}{*}{$\begin{array}{l}\text { Estimated exo- } \\
\text { thermic effect } \\
\text { at } 950^{\circ} \mathrm{C}\end{array}$} \\
\hline Ternp & Time & & & \\
\hline $\begin{array}{l}{ }^{\circ} \mathrm{C} \\
750 \\
750 \\
850 \\
880 \\
880\end{array}$ & $\begin{array}{r}\text { hr } \\
2 \\
168 \\
168 \\
26 \\
74 \\
120 \\
6 \\
24\end{array}$ & $\begin{array}{r}\text { Percent } \\
42.3 \\
42.0 \\
35.1 \\
38.5 \\
26.4 \\
4.3 \\
\text { (a) } \\
5.5\end{array}$ & $\begin{array}{l}\text { None } \\
(\mathbf{a}) \\
(\mathbf{a}) \\
(\mathbf{a}) \\
\gamma-\mathrm{Al}_{2} \mathrm{O}_{3} \\
\gamma-\mathrm{Al}_{2} \mathrm{O}_{3} \\
\gamma-\mathrm{Al}_{2} \mathrm{O}_{3} \\
\gamma-\mathrm{Al}_{2} \mathrm{O}_{3}\end{array}$ & $\begin{array}{c}\text { Large. } \\
\text { Do. } \\
\text { Medium. } \\
\text { Do. } \\
\text { Do. } \\
\text { Very small. } \\
\text { Do. } \\
\text { Do. }\end{array}$ \\
\hline $\begin{array}{l}\text { Air-quenched after heating to start of exothermic heat e } \\
6^{\circ} \mathrm{C} / \mathrm{min} \text {. } \\
\text { Air-quenched after heating to maximum of exotherm } \\
\text { effect at } 6^{\circ} \mathrm{C} / \mathrm{min} \text {. }\end{array}$ & ffect at & $\begin{array}{l}43.5 \\
10.0\end{array}$ & $\begin{array}{r}\text { None } \\
\gamma-\mathrm{Al}_{2} \mathrm{O}_{3}\end{array}$ & $\begin{array}{l}\text { Large. } \\
\text { None. }\end{array}$ \\
\hline
\end{tabular}

a Not determined.

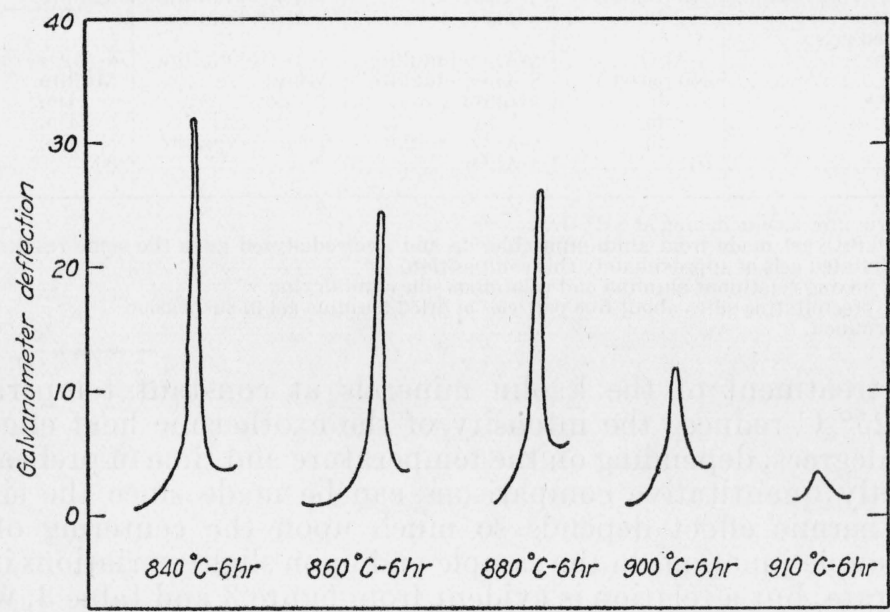

FIGURE 3.-Relation of size of exothermic heat effect, beginning at $925^{\circ} \mathrm{C}$ in Zettlitz kaolin, to temperature of preliminary heat treatment.

The coprecipitated gels described in section II gave exothermic effects at the same temperature and of approximately the same intensity as the kaolin minerals. The heating curves for the $\mathrm{Al}_{2} \mathrm{O}_{3} \cdot \mathrm{SiO}_{2}$ gel and $\mathrm{Al}_{2} \mathrm{O}_{3} \cdot 2 \mathrm{SiO}_{2}$ gel are given in figure 4 . In the other coprecipitated gels the heat effects were of the same character and at the same temperature as the two shown in figure 4, but the effect was slightly less intense in the case of the $2 \mathrm{Al}_{2} \mathrm{O}_{3} \cdot \mathrm{SiO}_{2}$ gel and much less in the case of the $4 \mathrm{Al}_{2} \mathrm{O}_{3} \cdot \mathrm{SiO}_{2}$ and $\mathrm{Al}_{2} \mathrm{O}_{3} \cdot 4 \mathrm{SiO}_{2}$ gels. Heat treatments of these gels at constant temperatures just below $925^{\circ} \mathrm{C}$ resulted in reduced intensity of the heat effect just as in the kaolin minerals. 


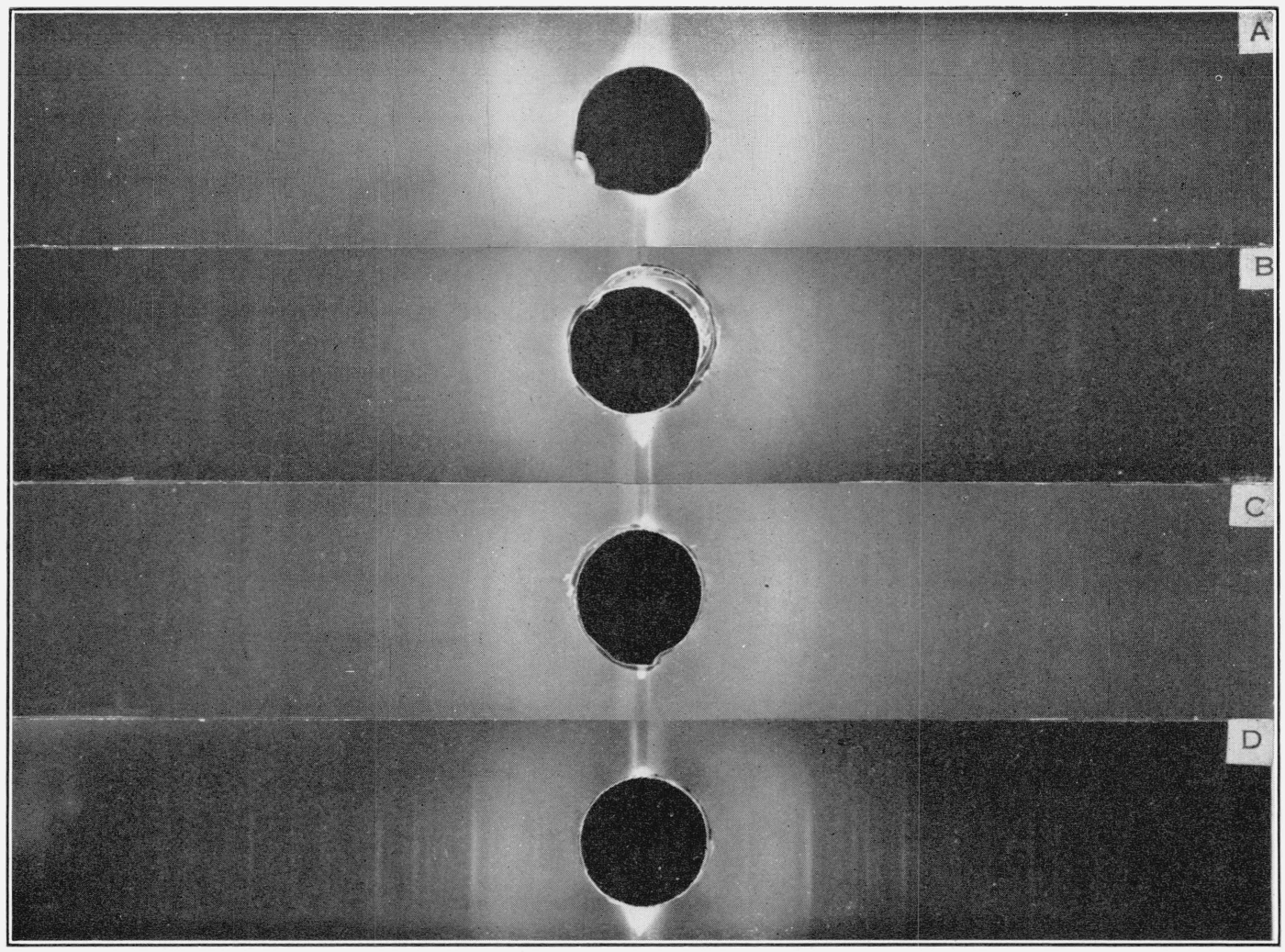

FIGURE 2.-X-ray patterns of the kaolin minerals after heat treatment.

A, Kaolinite (Zettlitz) heated to beginning of exothermic heat effect; B, Kaolinite (Zettlitz) heated to maximum of exothermic heat effect; C, Dickite heated above exothermic heat effect (about $1,000^{\circ} \mathrm{C}$.); D, Mullite formed by heating kaolinite to $1,350^{\circ} \mathrm{C}$. in $3 \frac{1}{2}$ hours. 
Gels $\mathrm{A}$ and $\mathrm{C}$ gave small exothermic heat effects at the same temperature and of the same character as kaolin and the coprecipitated gels, but none were observed in gels B and D.

X-ray patterns were made of samples of these gels (except the $4 \mathrm{Al}_{2} \mathrm{O}_{3}$. $\mathrm{SiO}_{2}$ and gels $\mathrm{B}$ and $\mathrm{D}$ ) which had been air-quenched immediately before the exothermic effect began and immediately after the maximum of the effect was reached. The results are given in table 2 . In addition, samples of the $\mathrm{Al}_{2} \mathrm{O}_{3} \cdot 2 \mathrm{SiO}_{2}$ gel were air-quenched from several intermediate temperatures between the start and maximum of the exothermic heat effect, and X-rayed. These all showed mullite as the only crystalline phase, the patterns increasing in intensity with increasing temperature.

The crystallization of $\gamma-\mathrm{Al}_{2} \mathrm{O}_{3}$ from amorphous forms of $\mathrm{Al}_{2} \mathrm{O}_{3}$ takes place at much lower temperatures when only $\mathrm{Al}_{2} \mathrm{O}_{3}$ is present than it does when $\mathrm{Al}_{2} \mathrm{O}_{3}$ is associated with a considerable amount of $\mathrm{SiO}_{2}$ (as in dehydrated kaolin) as is shown by the following experiments.

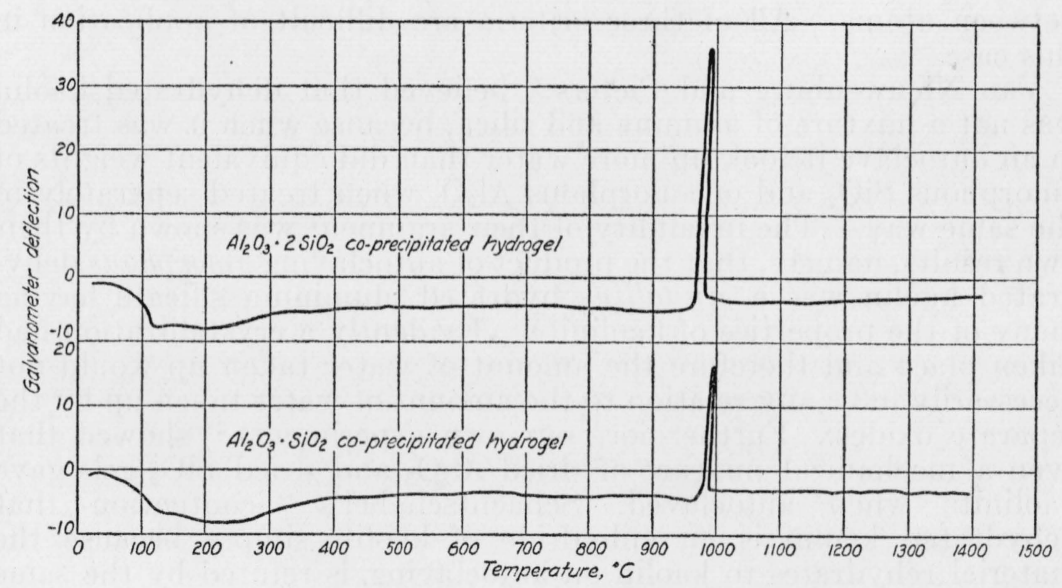

FIGURE 4.-Heating curves of synthetic alumina-silica gels.

Samples of amorphous $\mathrm{Al}_{2} \mathrm{O}_{3}$ gel (prepared by precipitating a solution of $\mathrm{AlCl}_{3}$ with $\mathrm{NaOH}$ in the presence of phenol red as an indicator) were heated at $6^{\circ} \mathrm{C} / \mathrm{min}$ to certain temperatures, air-quenched and X-rayed. Faint patterns of $\gamma-\mathrm{Al}_{2} \mathrm{O}_{3}$ were obtained from samples airquenched from 600 and $700^{\circ} \mathrm{C}$, and much stronger patterns from 800 and $900^{\circ} \mathrm{C}$ samples. All these temperatures are in the temperature range in which dehydrated kaolin and coprecipitated gels are still amorphous. The formation of $\gamma-\mathrm{Al}_{2} \mathrm{O}_{3}$ evidently occurs over a broad range of temperature since a differential heating curve shows no heat effect associated with the phase change. Other samples of amorphous $\mathrm{Al}_{2} \mathrm{O}_{3}$ (prepared by heating aluminum nitrate for 16 hours at $500^{\circ} \mathrm{C}$ ) showed two broad exothermic heat effects, one beginning at about $725^{\circ} \mathrm{C}$ and ending at about $800^{\circ} \mathrm{C}$, the other beginning at about $1,000^{\circ} \mathrm{C}$ and ending at about $1,050^{\circ} \mathrm{C}$. The first of these effects ${ }^{26}$ is due to the crystallization of $\gamma-\mathrm{Al}_{2} \mathrm{O}_{3}$ from amorphous $\mathrm{Al}_{2} \mathrm{O}_{3}$, as evidenced by X-ray patterns of samples air-quenched after heating to

\footnotetext{
${ }_{26}^{26}$ The second effect is due to the inversion of $\gamma-\mathrm{Al}_{2} \mathrm{O}_{3}$ to corundum.
} 
700 and $800^{\circ} \mathrm{C}$, which gave no pattern and the pattern of $\gamma-\mathrm{Al}_{2} \mathrm{O}_{3}$, respectively.

Differential heating curves of amorphous $\mathrm{SiO}_{2}$ gel showed no heat effects up to $1,300^{\circ} \mathrm{C}$, nor did samples air-quenched from temperatures up to $1,300^{\circ} \mathrm{C}$ show any crystallinity.

\section{(b) THE NATURE OF DEHYDRATED KAOLIN}

The question mentioned previously as to whether dehydrated kaolin is to be considered a mixture of amorphous $\mathrm{Al}_{2} \mathrm{O}_{3}$ and amorphous $\mathrm{SiO}_{2}$, or an amorphous aluminum silicate compound, is a difficult one to answer conclusively. Since dehydrated kaolin is amorphous it is certainly not a compound with the ionic lattice characteristic of the crystalline state. The criteria of an amorphous compound, if such an entity exists, must be: (1) Random arrangement of the units of the compound; (2) lack of definite melting point; (3) definite proportions of component atoms; (4) shared-electron bonds between atoms. All of these criteria are difficult of application in this case.

Van Nieuwenburg and Pieters ${ }^{27}$ believed that dehydrated kaolin was not a mixture of alumina and silica, because when it was treated in an autoclave it took up more water than did equivalent weights of amorphous $\mathrm{SiO}_{2}$ and of amorphous $\mathrm{Al}_{2} \mathrm{O}_{3}$ when treated separately in the same way. The invalidity of their argument was shown by their own results, namely, that the product of autoclaving amorphous dehydrated kaolin was a crystalline hydrated aluminum silicate having many of the properties of kaolinite. Evidently a crystallization had taken place and therefore the amount of water taken up would not necessarily have any relation to the amount of water taken up by the separate oxides. Furthermore our own experiments ${ }^{28}$ showed that even a mechanical mixture of dried $\mathrm{Al}_{2} \mathrm{O}_{3}$ and dried $\mathrm{SiO}_{2}$ gels gave kaolinite when autoclaved. Schachtschabel's ${ }^{29}$ contention that dehydrated kaolin is an anhydride of kaolin, simply because the material rehydrates to kaolin on autoclaving, is refuted by the same facts.

The authors believe that the mixture hypothesis is a simpler and more probable explanation of the results given in this paper. Such a mixture would necessarily be an exceedingly intimate one, possibly even a molecular dispersion of alumina in silica, differing both from a gross mechanical mixture and from a true chemical compound. The following line of reasoning is given in support of this viewpoint as opposed to the amorphous compound hypothesis.

Dehydrated kaolin and coprecipitated gels, for example $\mathrm{Al}_{2} \mathrm{O}_{3} \cdot 2 \mathrm{SiO}_{2}$ gel, resemble each other in the following points: (1) they both show a sharp, intense exothermic heat effect at 925 to $985^{\circ} \mathrm{C}$; (2) they are both amorphous in the temperature range from about $700^{\circ} \mathrm{C}$ up to the start of the exothermic heat effect, when heated at $6^{\circ} \mathrm{C} / \mathrm{min}$; (3) heat treatment at constant temperature just below $925^{\circ} \mathrm{C}$ reduces, or completely eliminates, the heat effect in both cases; (4) the $\mathrm{Al}_{2} \mathrm{O}_{3}$ is practically completely soluble in $\mathrm{HCl}$ in both cases; (5) they both

${ }^{27}$ Rec. trav. chim. 48, 27-36 (1929).

${ }_{28}$ Detailed report in preparation for publication.

${ }_{29}$ Chem. Erde 4, 395-419 (1930). 
form kaolin to approximately the same extent when heated with water in an autoclave at high temperatures (about $300^{\circ} \mathrm{C}$.) ${ }^{30}$

In view of the facts it may be concluded that dehydrated kaolin and a coprecipitated gel of the same composition $\left(\mathrm{Al}_{2} \mathrm{O}_{3} \cdot 2 \mathrm{SiO}_{2}\right)$ are very similar in internal structure and that evidence as to the nature of either may be considered evidence as to the nature of both. The following evidence is advanced for the hypothesis that both are mixtures and not chemical compounds:

(1) Gels A and $\mathrm{C}$ give exothermic effects at the same temperature and of the same character as the coprecipitated gels, though less intense. If it be assumed that any compound formation in the coprecipitated gels must take place by reaction between ions at the moment of precipitation, then compound formation in gels $\mathrm{A}$ and $\mathrm{C}$ would be highly improbable under the conditions of their preparation, and the exothermic effect observed could not be due to the decomposition of an aluminum silicate compound with simultaneous crystallization of $\gamma-\mathrm{Al}_{2} \mathrm{O}_{3}$.

(2) An aluminum silicate formed by reaction in aqueous solution would be almost completely hydrolyzed ${ }^{31}$ since aluminum hydroxide is such a very weak base and silicic acid is such a very weak acid.

(3) The alumina is practically completely soluble in dilute $\mathrm{HCl}$ in both dehydrated kaolin and the coprecipitated gels. This is not true of any known crystalline aluminum silicate.

(4) Kaolin which has been calcined at temperatures between 550 and $800^{\circ} \mathrm{C}$ exhibits pozzolanic properties with lime solutions, owing largely to the formation of a hydrated monocalcium silicate. ${ }^{32}$ This behavior is similar to that shown by silica gel and by diatomaceous silica.

(5) A mechanical mixture of dried $\mathrm{Al}_{2} \mathrm{O}_{3}$ gel and dried $\mathrm{SiO}_{2}$ gel is converted to kaolinite on autoclaving at $312^{\circ} \mathrm{C}$, the same as are dehydrated kaolin and coprecipitated gels.

\section{(c) DISCUSSION OF RESULTS}

The first crystalline material to be formed after the endothermic dissociation of kaolin is $\gamma-\mathrm{Al}_{2} \mathrm{O}_{3}$. When the sample is heated at moderately rapid rates $\left(2^{\circ} \mathrm{C}\right.$ or more per minute), this formation of crystalline material is closely related to the exothermic effect beginning at $925^{\circ} \mathrm{C}$, as is shown by the X-ray patterns on samples removed from the furnace immediately before and immediately after the evolution of heat occurs. In samples heated for long periods $\gamma-\mathrm{Al}_{2} \mathrm{O}_{3}$ may be formed at temperatures as much as $50^{\circ} \mathrm{C}$ lower than this. This long heating at temperatures lower than $925^{\circ} \mathrm{C}$ causes partial or complete transformation of the amorphous $\mathrm{Al}_{2} \mathrm{O}_{3}$ to $\gamma-\mathrm{Al}_{2} \mathrm{O}_{3}$, and also causes partial or complete elimination of the exothermic effect in subsequent heatings.

Since the formation of $\gamma-\mathrm{Al}_{2} \mathrm{O}_{3}$ in the dehydrated kaolin takes place rapidly with a violent evolution of heat, while in the amorphous forms of pure alumina crystallization of $\gamma-\mathrm{Al}_{2} \mathrm{O}_{3}$ takes place over a long temperature interval at much lower temperatures, it is justifiable to conclude that the amorphous silica has a retarding action on this crystallization. We may assume that in pure amorphous alumina 
there is a random structure and consequently individual molecules have different activities during heating. The change to the crystalline form, therefore, takes place gradually over a wide range of temperatures. In the dehydrated kaolin minerals, or in intimate mixtures of amorphous alumina and silica, however, the activity of the alumina molecules presumably is restrained by the rigid silica structure so that all the $\mathrm{Al}_{2} \mathrm{O}_{3}$ molecules have the same activity at a given temperature, and when, with increasing temperature the activity of all the $\mathrm{Al}_{2} \mathrm{O}_{3}$ molecules exceeds a certain "threshold value", the crystallization of $\gamma-\mathrm{Al}_{2} \mathrm{O}_{3}$ takes place very rapidly throughout the whole mass. This "threshold value" might be considered analogous to the energy of activation in gaseous reactions.

A similar case of repression of a phase change in the solid state by the presence of silica was observed by Geilmann, Klemm, and Meisel ${ }^{33}$ in the mineral nontronite $\left(\mathrm{Fe}_{2} \mathrm{O}_{3} \cdot 3 \mathrm{SiO}_{2} \cdot 5 \pm \mathrm{H}_{2} \mathrm{O}\right)$. When this mineral is dehydrated, $\gamma-\mathrm{Fe}_{2} \mathrm{O}_{3}$ and amorphous $\mathrm{SiO}_{2}$ are formed, and on further heating the $\gamma-\mathrm{Fe}_{2} \mathrm{O}_{3}$ inverts to $\alpha-\mathrm{Fe}_{2} \mathrm{O}_{3}$ only at temperatures above $1,000^{\circ} \mathrm{C}$, whereas pure $\gamma-\mathrm{Fe}_{2} \mathrm{O}_{3}$ inverts to $\alpha-\mathrm{Fe}_{2} \mathrm{O}_{3}$ around $600^{\circ} \mathrm{C}$. The investigators ascribe the stabilization of the lower temperature form to the effect of the rigid amorphous silica structure.

Some experiments of our own on the relative crystallizability of $\mathrm{Fe}_{2} \mathrm{O}_{3}$ gels and coprecipitated $\mathrm{Fe}_{2} \mathrm{O}_{3} \cdot 2 \mathrm{SiO}_{2}$ gels confirm the hypothesis of the restraining effect of silica on crystallization. Pure $\mathrm{Fe}_{2} \mathrm{O}_{3}$ gel when heated at $6^{\circ} \mathrm{C} / \mathrm{min}$ to temperatures as low as $400^{\circ} \mathrm{C}$ gave an X-ray pattern of $\alpha-\mathrm{Fe}_{2} \mathrm{O}_{3}$, whereas the $\mathrm{Fe}_{2} \mathrm{O}_{3} .2 \mathrm{SiO}_{2}$ gel still failed to show any crystallization when heated to $800^{\circ} \mathrm{C}$ at the same rate.

The rigidity of the structure in the amorphous forms of silica (glass and gel) is shown by the resistance of these forms to flow and the sluggishness with which they crystallize even when heated to very high temperatures. ${ }^{34}$ A sample of silica gel, for instance, which we heated to $1,300^{\circ} \mathrm{C}$ at $6^{\circ} \mathrm{C} / \mathrm{min}$ failed to show any X-ray pattern of a crystalline material.

The data in table 2 show that the coprecipitated gels resemble dehydrated kaolin in remaining amorphous up to the start of the exothermic heat effect, but differ in the crystalline phase present after the heat evolution has taken place, namely, $\gamma-\mathrm{Al}_{2} \mathrm{O}_{3}$ in the case of kaolin and mullite in the case of the gels (mullite $+\gamma-\mathrm{Al}_{2} \mathrm{O}_{3}$ in the case of the gels high in $\mathrm{Al}_{2} \mathrm{O}_{3}$ ). However, table 2 shows also that in kaolin heated to temperatures only slightly past the maximum of the heat effect, mullite is already present in crystals large enough to diffract X-rays. These data indicate that $\gamma-\mathrm{Al}_{2} \mathrm{O}_{3}$ formation is an intermediate step in mullite formation in kaolin; in fact, it appears to have a sort of "trigger action" with respect to mullite formation. Since this is the case in kaolin, it might be assumed that $\gamma-\mathrm{Al}_{2} \mathrm{O}_{3}$ is formed momentarily as an intermediate compound in the case of the gels. If this be true, the reaction to form mullite must be extremely rapid, for samples of gels air-quenched from temperatures intermediate between the start and maximum of the exothermic heat effect showed mullite as the only crystalline phase.

${ }^{33}$ Naturwissenschaften 20, 639-640 (1932).

34 Sosman, The Properties of Silica, p. 97-99, 473-475. (The Chemical Catalog Co., New York, N. Y.) 
The internal structure of the material appears to determine which compound is formed. As shown by Gruner ${ }^{35}$ the structure of the kaolin minerals is essentially lamellar. After dehydration with accompanying loss of crystal structure, the arrangement of the $\mathrm{Al}_{2} \mathrm{O}_{3}$ and $\mathrm{SiO}_{2}$ molecules in the dehydrated kaolin is such that when crystallization begins, $\gamma-\mathrm{Al}_{2} \mathrm{O}_{3}$ forms first, followed shortly by mullite, while in the coprecipitated gels the molecular arrangement is such that mullite is the first observable crystalline phase formed.$^{36}$

The intensity of the exothermic effect depends in part upon the intimacy of contact between the alumina and silica. In the $\mathrm{Al}_{2} \mathrm{O}_{3} \cdot 2 \mathrm{SiO}_{2}, \quad \mathrm{Al}_{2} \mathrm{O}_{3} \cdot \mathrm{SiO}_{2}$, and $2 \mathrm{Al}_{2} \mathrm{O}_{3} \cdot \mathrm{SiO}_{2}$ coprecipitated gels the exothermic effect is of about the same magnitude as in the kaolin minerals. The $4 \mathrm{Al}_{2} \mathrm{O}_{3} \cdot \mathrm{SiO}_{2}$ and $\mathrm{Al}_{2} \mathrm{O}_{3} \cdot 4 \mathrm{SiO}_{2}$ gels show small heat effects. In the former the small amount of silica present is sufficient to keep only a part of the $\mathrm{Al}_{2} \mathrm{O}_{3}$ from crystallizing until $925^{\circ} \mathrm{C}$, most of the $\mathrm{Al}_{2} \mathrm{O}_{3}$ crystallizing over a broad temperature range below $925^{\circ} \mathrm{C}$ without observable heat effect. In the latter case there is sufficient silica present, but the amount of $\mathrm{Al}_{2} \mathrm{O}_{3}$ is small and therefore the heat effect is small. The optimum ratio of $\mathrm{Al}_{2} \mathrm{O}_{3}: \mathrm{SiO}_{2}$ for a large heat effect appears to lie between $1: 1$ and $1: 2$. In gels $A$ and $C$ the exothermic effects are of the same character and at the same temperature as in the coprecipitated gels but much less intense. This fact indicates that the character of the contact of the $\mathrm{Al}_{2} \mathrm{O}_{3}$ and $\mathrm{SiO}_{2}$ in these two gels is the same as in the coprecipitated gels, but that the extent of contact is less.

\section{SUMMARY}

When the kaolin minerals, kaolinite and dickite, are heated at rates from 5 to $30^{\circ} \mathrm{C} / \mathrm{min}$ there are two large and significant heat effects. The lower one, a broad but intense endothermic effect, is associated with the loss of water and the dissociation into an exceedingly intimate mixture of amorphous alumina and amorphous silica. The upper one, a sharp and intense exothermic effect, is associated with the formation of $\gamma-\mathrm{Al}_{2} \mathrm{O}_{3}$ from amorphous $\mathrm{Al}_{2} \mathrm{O}_{3}$. The evidence supports the conclusion that the formation of $\gamma-\mathrm{Al}_{2} \mathrm{O}_{3}$ at much higher temperatures in the kaolin minerals than in amorphous alumina is due to the restraining action of the rigid amorphous $\mathrm{SiO}_{2}$ network on the crystallization of the $\mathrm{Al}_{2} \mathrm{O}_{3}$. In synthetic alumina-silica gels an exothermic effect at the same temperature and of the same character is observed with crystallization of mullite (or of mullite and $\gamma-\mathrm{Al}_{2} \mathrm{O}_{3}$ ) instead of $\gamma-\mathrm{Al}_{2} \mathrm{O}_{3}$. Apparently the nature of the resultant crystalline phase depends upon the internal structure of the material.

Washington, March 23, 1935.

${ }_{35}^{35}$ See footnote 4, p. 616.

${ }^{36}$ Since by Hess' law the heat evolved by the sum of the reactions: Amorphous $\mathrm{Al}_{2} \mathrm{O}_{3} \rightarrow \gamma-\mathrm{Al}_{2} \mathrm{O}_{3}$ $\gamma-\mathrm{Al}_{2} \mathrm{O}_{3}$ tamorphous $\mathrm{SiO}_{2} \rightarrow$ mullite 